\title{
For Whom is Distance Learning Suitable? The Relationship between Distance Learning, Executive Functions, and Academic Achievements
}

\author{
Running Head: Executive Function and Distance Learning
}

Ayelet Harel-Gadassi

Efrata College of Education, Jerusalem, Israel

Received November 15, 2021; Revised December 22, 2021; Accepted January 25, 2022

\section{Cite This Paper in the following Citation Styles}

(a): [1] Ayelet Harel-Gadassi , "For Whom is Distance Learning Suitable? The Relationship between Distance Learning, Executive Functions, and Academic Achievements," Universal Journal of Educational Research, Vol. 10, No. 2, pp. 129-136, 2022. DOI: 10.13189/ujer.2022.100202.

(b): Ayelet Harel-Gadassi (2022). For Whom is Distance Learning Suitable? The Relationship between Distance Learning, Executive Functions, and Academic Achievements. Universal Journal of Educational Research, 10(2), 129-136. DOI: 10.13189/ujer.2022.100202.

Copyright $\odot 2022$ by authors, all rights reserved. Authors agree that this article remains permanently open access under the terms of the Creative Commons Attribution License 4.0 International License

\begin{abstract}
The current study examines whether there are differences in academic success between classroom learning and distance learning and further evaluates which characteristics are associated with lower achievement in distance learning, in contrast to learning in a classroom setting. A cross-sectional design was employed with 118 students in higher education who completed the Behavior Rating Inventory of Executive Functioning-Adult Version, the Self-Efficacy Questionnaire, and the Academic Motivation Scale. The students were also asked to report their GPAs in the first and second semesters. In agreement with the majority of previous studies, no differences in academic achievement were found between classroom and distance learning. An innovative finding of this study is that executive functions are directly and indirectly associated with academic achievements in distance learning. Self-efficacy and intrinsic motivation mediate these relationships. The use of distance education technology versus traditional classroom learning to teach college students does not affect their academic performance. Thus, it is advisable to develop this type of instruction and allow students who are suited for and interested in distance learning to complete a portion of their courses in this way, as this change will not adversely affect their academic performance. Additionally, in distance learning, it is crucial that students with low executive
\end{abstract}

functions be identified and given a comprehensive support structure, including conveying learning strategies to them and strengthening their senses of self-efficacy and intrinsic motivation.

Keywords Distance Learning, Executive Functions, Academic Self-efficacy, Motivation, Academic Achievements

\section{Introduction}

In December 2019, coronavirus disease 2019 (COVID-19) began to spread around the globe. To reduce this spread and curb morbidity, people were asked to maintain social distance. This and other safety measures were also applied to educational settings. Overnight, many institutions of higher education transitioned to distance learning. This situation provided an opportunity to examine the impact of distance learning on students' outcomes, which is the aim of the present study.

Distance learning is not new for higher education. It has a history that spans almost three decades and has effected changes in the ways in which learning occurs and information is communicated [1]. During this period, the 
usage of distance learning platforms in higher education has increased, with technological development having driven this change $[2,3]$. Simply put, distance learning has evolved in tandem with the technological transformations that the world has undergone. In the past, distance learning was usually asynchronous, meaning that there was no need to attend classes in a specific physical environment or at a particular time. Students received and accessed the instructor-generated content to engage in their studies. They subsequently completed and submitted academic assignments and, often, collaborative activities. Instructors were available through mediated means, such as email. In recent decades, synchronous distance learning has become more common, and it includes live video, with instructors and students engaged in interactive participation [4,5].

Distance education offers many benefits. It often minimizes the difficulty of providing access to learning for those who are geographically distant from an academic institution [1], and it allows students the flexibility to take classes at different times [6]. It also reduces education costs [7]. However, in the context of distance learning, students cannot develop the socialization and interpersonal skills that normally accompany traditional learning methods [8].

Evidence from comparative samples shows that distance students most often achieve learning outcomes that are not significantly different from those of students enrolled in classroom-based education, or their outcomes may even be positively skewed toward higher achievement $[8,9,10]$. However, distance education has been criticized for higher attrition rates, particularly in those distance education systems that provide low levels of student support and those that use fewer interactive media $[10,11]$. Thus, it seems that there are students for whom distance learning is suitable, while there are others who fail to meet academic requirements when they learn in this way. This study examines factors that predict failure when students learn from a distance. Specifically, the variables of executive functions, self-efficacy, and motivation are examined.

Distance courses require a relatively high level of autonomy and self-regulation on the part of the learners because of the physical separation from the course instructor or from their peers $[12,13]$. For example, in distance learning, if students do not understand a question in class, it will be more difficult for them to find the answer because they have no direct contact with peers. Moreover, the physical distance during the lesson may cause additional distractions, given that these are usually more frequent outside the physical space of the classroom. Hence, these students must have the ability to use self-regulation skills.

Self-regulated learners are characterized as committed participants who efficiently control their own learning experiences. They can direct their thoughts and actions toward achieving their goals as a result of their intact executive functions. Executive functions are neurocognitive processes that promote self-regulation at the basic neurocognitive and metacognitive levels. At the neurocognitive level, executive functions give rise to control over attention and working memory, and they facilitate freedom from distractibility [14]. At the metacognitive level, executive functions play a foundational role in one's analysis of the demands of a learning task, setting of goals, selection and deployment of strategies, planning and allocation of resources to meet the task's demands, organization and rehearsal of information to be learned, self-monitoring of one's effectiveness, and searching for help when one does not understand $[12,15,16,17]$. Students with risk factors for executive function weaknesses are at risk of poor self-regulatory skills and academic difficulties [18]. Thus, executive functions are necessary for learning in general. The hypothesis of the present study is that executive functions will be even more essential in the case of distance learning due to the autonomous nature of this type of learning.

Executive functions may also influence learning through self-efficacy and motivation. The key concept of self-efficacy in sociocognitive theory refers to "a person's self-evaluation of his ability to execute the courses of action required for the successful attainment of a certain goal” $[19,20]$. Students with more effective executive function were found to have higher self-efficacy [21]. As a result, in academic settings, it can be assumed that learners with high self-efficacy have higher motivation to learn, which leads to higher academic achievement, because those learners believe that they have the ability to achieve their goals [22,23,24]. For example, students who know what they need to do to achieve a high score on a test will experience a sense of higher self-efficacy. This will lead them to invest greater effort in test preparation, and their probability of earning a good score will be higher. On the other hand, students who do not know what they need to do to prepare for the test will experience a low sense of self-worth and, as a result, will simply stop studying and fail to prepare themselves for the assessment.

Motivation is also necessary for learning because learning is a lifelong process. For one to continuously achieve high grades, a high level of motivation is crucial. Motivation is the force that encourages students to confront difficult and challenging circumstances [25]. It can be categorized in three ways: intrinsic motivation, extrinsic motivation, and amotivation [26,27]. Intrinsic motivation propels an activity that is completed primarily for one's own feeling of contentment, without any anticipation of external feedback. The key factors that trigger intrinsic motivation are a sense of challenge, curiosity, control, and fantasy [28]. Intrinsic motivation and academic achievement are significantly and positively linked to one another [29]. In contrast, extrinsic motivation means that external activities are driven by factors such as rewards, compulsions, or punishments. Individuals are extrinsically motivated if they receive any type of reward or are under any pressure or compulsion to complete an activity [25,30]. Motivation can be cultivated extrinsically at the initial stage and transformed into intrinsic motivation as the 
learning process deepens [31]. Amotivation, in contrast, means that individuals are unable to motivate themselves, whether intrinsically or extrinsically $[27,28]$.

In distance learning, students can easily become disconnected from the course and may experience negative feelings that, in turn, can adversely affect their motivation. In addition, as previously mentioned, due to the autonomous nature of distance learning, students are required to regulate the majority of their motivation independently $[12,13]$. Thus, the present study addresses motivation in distance learning.

A review of previous literature suggests that executive functions are important for learning in general. Moreover, the literature reports a relationship between executive functions, self-efficacy, motivation, and academic achievement. Given the autonomous nature of distance learning, it was hypothesized that executive functions, self-efficacy, and motivation will be even more necessary in the case of distance learning, while a weakness in these variables may predict failure when students learn from a distance. In sum, the aims of the current study are to a) examine whether there are differences in academic achievement between classroom and distance learning and b) evaluate which characteristics are associated with lower grades in distance learning, compared to classroom learning. In general, it is hypothesized that no significant differences will be found between academic achievement in classroom versus distance learning. In addition, less optimal self-regulation skills, less academic self-efficacy, and poorer motivation regulation are anticipated to be related to lower academic achievement in distance learning, compared to classroom learning. The findings from this study may shed light on the worthiness of developing distance learning programs, aid in selecting students who are suitable for learning in this style, and provide parameters for identifying students who may have difficulty with distance learning.

\section{Method}

\section{Participants and Procedure}

In 2020, approximately 313,600 students were enrolled in higher education in Israel [32]. In this cross-sectional study, the participants were recruited through a combination of convenience and snowball sampling methods. The participants included 118 students in higher education studying toward different professions: 20 males and 98 females, between the ages of 20 and 50 years $(M=$ 28.47 years, $S D=7.30)$. Twenty-three $(19.5 \%)$ were enrolled in professional studies, 72 (61\%) in BA degree studies, 21 (17.8\%) in MA degree studies, and two (1.7\%) in $\mathrm{PhD}$ degree studies. Twenty-four (20.3\%) of the students were diagnosed with a learning disability, and $13 \%$ were diagnosed with attention-deficit/hyperactivity disorder (ADHD). Following approval by the college ethics committee, the online questionnaire was distributed via a link to private emails or WhatsApp groups known to the author through family ties, friendships, or places of employment. Each person" contacted was asked to distribute an online link to friends, family members, or work colleagues who were studying in higher education. The questionnaire was answered anonymously. Informed consent was requested on the first screen, and only participants who marked "agree" were referred to the questionnaire. Data were collected in August 2020, at the beginning of the pandemic's second wave in Israel. Participation in the research was voluntary, with the incentive of gift certificates to be awarded to three participants chosen by a lottery. Participants received an explanation of the study and its purpose at the beginning of the questionnaire and assurance of anonymity.

\section{Measures}

The Behavior Rating Inventory of Executive Functioning-Adult Version [33]. The Behavior Rating Inventory of Executive Functioning-Adult Version (BRIEF-A) is a widely used measure designed to assess adults' executive functions or self-regulation in their everyday environments. BRIEF-A contains 75 items scored on a three-point Likert scale, with higher scores indicating poorer executive function. BRIEF-A yields an overall score (Global Executive Composite) composed of two index scores, the Behavioral Regulation Index and the Metacognition Index. The Behavioral Regulation Index is comprised of four scales (Inhibit, Shift, Emotional Control, and Self-Monitor), and the Metacognition Index is comprised of five scales (Initiate, Working Memory, Plan/Organize, Task Monitor, and Organization of Materials). An internal reliability of .97 for BRIEF-A was used in the current study.

Self-Efficacy Questionnaire [34]. The Self-Efficacy Questionnaire (SEQ) is a brief questionnaire containing 24 items that are hypothesized to represent three domains of self-efficacy: (1) social self-efficacy, which refers to one's perceived capability to foster peer relationships and display assertiveness; (2) academic self-efficacy, which is concerned with the perceived capability to manage one's own learning behavior, to master academic subjects, and to fulfill academic expectations; and (3) emotional self-efficacy, which pertains to one's perceived capability to cope with negative emotions. The current study used only the academic self-efficacy items. Each item must be scored on a five-point scale, on which $1=$ not at all and $5=$ very well. In the current study, an internal reliability of .85 was used for the SEQ - academic self-efficacy.

Academic Motivation Scale [35]. This questionnaire is designed to assess motivation among students. It consists of five subscales. Each scale includes four items, which are possible responses to the question, "Why are you pursuing higher education?” The scales include intrinsic motivation ("Because I experience pleasure and satisfaction while 
learning new things"), three types of external motivation, external regulation ("In order to find a high-paying job later on"), introjected regulation ("Because of the fact that when I succeed in school, I feel important"), identified regulation ("Because eventually it will enable me to enter the job market in a field that I like"), and amotivation ("I really feel that I am wasting my time in school"). Response choices for each item were rated on a seven-point Likert scale from 0 (does not correspond at all) to 7 (corresponds exactly). The internal reliability of the AMS used in the current study was .93 for intrinsic regulation, .69 for external regulation, .82 for introjected regulation, .70 for identified regulation, and .80 for amotivation.

Demographic Questionnaire. All students completed a demographic questionnaire regarding age, gender, marital status, education, existence of learning disabilities or ADHD, use of medication for ADHD, and academic achievement.

\section{Statistical Analysis}

To examine possible differences in academic achievement between classroom and distance learning, a paired sample $t$-test was conducted. The study compared the GPA in the first semester, when learning took place in classrooms, to the GPA in the second semester, when learning was at a distance. A score gap variable was then calculated by subtracting each student's second-semester GPA from their first-semester GPA. Larger gaps indicated lower grades in distance learning when compared to classroom learning. To evaluate which characteristics were associated with a lower grade in distance learning versus classroom learning, the Pearson correlation coefficient was calculated. To test the hypothesis that executive functions are directly associated with the score gap variable and indirectly mediated by academic self-efficacy and motivation, a structural equation modeling (SEM) analysis was conducted using the AMOS software. The model included only the variables that correlate with the score gap variable: executive functions, academic self-efficacy, and intrinsic motivation.

\section{Results}

A paired sample $t$-test revealed no significant differences between GPA in the classroom $(M=87.6, S D=$ 13.30) and in distance learning $(M=87.30, S D=9.01)$, $\mathrm{T}[108]=.30, p>.05$.

Significant positive correlations emerged between executive functions, academic self-efficacy, intrinsic motivation, and the score gap variable, indicating that receiving a lower grade in distance learning than in classroom learning is associated with less optimal executive functions, lower academic self-efficacy, and lower intrinsic motivation. The correlations between the different types of external motivation, amotivation, and the score gap variable were non-significant.

The model demonstrated a strong fit to the data, as evidenced by the following results: AIC $=45.376$, RMSEA $=.143$. As indicated in Figure 1, executive functions were directly and indirectly associated with the score gap variable. Significant correlations were found between executive functions and the score gap variable $(\beta=5.12$, C.R. = 1.62). Significant correlations were also found between executive functions and academic self-efficacy ( $\beta$ $=1.04$, C.R. $=-6.24$ ), between the academic self-efficacy variable and intrinsic motivation $(\beta=.58$, C.R. $=2.73)$, and between intrinsic motivation and the score gap variable $(\beta$ $=.94$, C.R. $=2.83$ ).

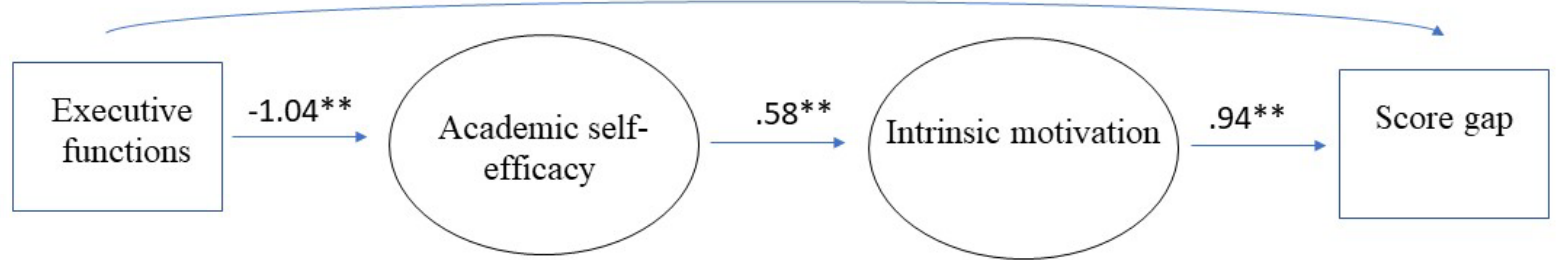

Figure 1. Association between Executive Functions, Academic Self-Efficacy, Motivation, and Academic Achievements: Structural Equation Model. 


\section{Discussion}

Distance learning in higher education began approximately three decades ago, and it is gaining momentum [1]. Although it offers many advantages and has improved significantly, disadvantages related to this teaching method persist. For example, it has been criticized for having higher attrition rates $[10,11]$. Hence, the aims of the current study were to examine whether there are differences in academic achievement between classroom and distance learning and to evaluate which characteristics are associated with a lower grade in distance learning versus learning in the traditional classroom, based on information provided by 118 higher-education students.

In agreement with the majority of previous studies, no difference in academic achievement was found between classroom and distance learning $[8,9,10,36]$. These findings suggest that the use of distance education technology to teach students, instead of traditional classroom learning, does not affect their academic performance. Contradictory findings were reported in another study, which found that students who learned in classrooms achieved significantly higher course grades than students who learned in distance learning [37]. However, the difference in GPA at the end of the semester did not reach statistical significance. Based on these findings and the benefits offered by distance learning, including flexibility in location [1] and time of learning [6] and the reduction of education costs [7], increasing and developing distance learning in academia are recommended.

The disadvantages of distance learning, specifically those related to the difficulty of developing socialization and interpersonal skills, have also been reported [8]. Additionally, some students fail to meet their academic requirements via this learning method [10,11]. In the current study, executive functions were both directly and indirectly associated with academic achievement in distance learning; as such, executive functions constitute one of the factors that predict success or failure when learning from a distance. This variable has already been found to be related to academic achievement in previous studies that have dealt with traditional classroom learning. The present study is innovative in its finding that executive functions are even more necessary in the case of distance learning than classroom, as a correlation was found between executive functions on the one hand and the gap between GPA scores in classroom versus distance learning on the other. That is, there was a greater gap in academic achievement between classroom and distance learning among students whose executive functions were less optimal. This finding is not surprising, since distance learning requires a relatively high level of autonomy and self-regulation due to students' inherent physical separation from both the course instructor and their peers $[12,13]$.
In addition, self-efficacy and intrinsic motivation were found to mediate the relationship between executive functions and academic achievement. These variables have been found to be related in previous studies that have examined this connection in the context of classroom learning [38,39]. The ability to use executive functions, such as goal setting, self-monitoring, self-evaluation, and strategy, strengthens students' sense of self-efficacy and allows them to develop greater confidence in their academic capabilities. High levels of self-efficacy influence intrinsic motivation, as students who believe that they have the means to perform successfully are apt to feel more emotionally involved; thus, they will engage and invest greater effort in the learning task. Academic achievement is consequently expected to be higher for these students. As in the case of executive functions, this study extends the literature regarding the importance of self-efficacy and intrinsic motivation in the case of distance learning, since a correlation was found between these factors on the one hand and the gap in academic achievements between classroom and distance learning on the other.

Finally, a correlation was found between internal, rather than external, motivation for academic achievement. The correlation between intrinsic motivation and academic achievement was also found in previous studies regarding classroom learning [28]. That is, students who learn for the pleasure and satisfaction that they derive from it are more likely to demonstrate better academic achievement. However, contrary to the findings of the present study, previous studies have also found that external motivation is associated with academic achievement in classroom learning. For example, students may participate in classroom activities because the teacher urges them to do so, and they will achieve better academic results through these efforts [40]. It is possible that the difference between these findings is related to the distinct characteristics of distance and classroom learning. Due to its autonomous nature, distance learning requires students to regulate most of their motivation on their own. Therefore, distance learning has greater significance for internal than for external motivation.

The practical implication of this study is that, given its benefits and the similar levels of academic achievement that were found in distance and classroom learning, distance learning is recommended as a valid option and should be promoted and developed. On the one hand, students with strong executive functions should be included in these programs. On the other hand, when an institution implements a distance learning program, students with low executive functions should be identified. These students should be offered comprehensive support that includes the imparting of learning strategies and a strengthening of their senses of self-efficacy and intrinsic motivation.

One of this study's strengths lies in the unique 
opportunity that was created by the COVID-19 pandemic to compare the academic achievements of the same students in distance and classroom learning. In addition, most of the previous studies included students who explicitly preferred distance learning programs to classroom programs. In contrast, participants in the present study included students who were forced into distance learning because of the pandemic. Students who choose distance learning rather than classroom programs may have different characteristics that are more appropriate for the former learning style than the latter, which may have skewed the prior research results.

However, since the pandemic had an unexpected impact on the entire world, including institutions of higher learning, lecturers were required to transition their courses to distance learning within only a few days, and the distance learning modality was not pre-planned. In further research, it will be worthwhile to examine the differences between distance and classroom learning, as well as the characteristics that make students more suitable to distance learning, in courses that were pre-planned for that delivery mode. Furthermore, the initial period of the coronavirus pandemic was an emotionally charged time for students, and this may have had an impact on the results of the study. Another limitation relates to the unequal ratio of female to male participants in the study. This gender gap resulted from the combination of convenience and snowball sampling method. Finally, the study addressed academic achievement rather than the students' experience in distance versus classroom learning or their preference regarding the type of learning. It would be appropriate to address this in further research as well.

\section{Conflict of Interest Statement}

The author has no conflicts of interest to disclose.

\section{Acknowledgments}

I am grateful to the participating students for their cooperation.

\section{REFERENCES}

[1] Moore, J. L., Dickson-Deane, C., \& Galyen, K., "e-Learning, online learning, and distance learning environments: Are they the same?", The Internet and Higher Education, vol. 14, no. 2, pp. 129-135, 2011. DOI: https://doi.org/10.1016/j.ih educ.2010.10.001

[2] Allen, I. E. \& Seaman J., "Online report card: Tracking online education in the United States", Babson Survey Research Group. Babson College, 231 Forest Street,
Babson Park, MA 02457, 2016.

[3] Casey, D. M., "The historical development of distance education through technology", TechTrends, vol. 52, no. 2, pp. 45-51, 2008.

[4] Anderson, T., \& Rivera-Vargas, P., "A critical look at educational technology from a distance education perspective", Digital Education Review, no. 37, pp. 208-229, 2020. DOI: https://doi.org/10.1344/der.2020.37.2 08-229.

[5] Sangrà, A., Vlachopoulos, D., \& Cabrera, N., "Building an inclusive definition of e-learning: An approach to the conceptual framework", International Review of Research in Open and Distributed Learning, vol. 13, no. 2, pp. 145-159, 2012. DOI: https://doi.org/10.19173/irrodl.v13i2. 1161.

[6] Sun, J. C. Y., \& Rueda, R., "Situational interest, computer self - efficacy and self - regulation: Their impact on student engagement in distance education", British journal of educational technology, vol. 43, no. 2, pp. 191-204, 2012. DOI: https://doi.org/10.1111/j.1467-8535.2010.0115 7.x.

[7] Hebebci, M. T., Bertiz, Y., \& Alan, S., "Investigation of views of students and teachers on distance education practices during the Coronavirus (COVID-19) Pandemic". International Journal of Technology in Education and Science (IJTES), vol. 4, no. 4, pp. 267-282, 2020.

[8] Gossenheimer, A. N., Bem, T., Carneiro, M. L. F., \& de Castro, M. S., "Impact of distance education on academic performance in a pharmaceutical care course" PloS one, vol. 12, no. 4, 2017. DOI: https://doi.org/10.1371/journal.pone. 0175117.

[9] Russell, T. L., The no significant difference phenomenon: As reported in 355 research reports, summaries and papers. North Carolina State University, 1999.

[10] Shachar, M., \& Neumann, Y., "Twenty years of research on the academic performance differences between traditional and distance learning: Summative meta-analysis and trend examination", MERLOT Journal of Online Learning and Teaching, vol. 6, no. 2, 2010.

[11] Yukselturk, E., Ozekes, S., \& Türel, Y. K., "Predicting dropout student: an application of data mining methods in an online education program", European Journal of Open, Distance and e-learning, vol. 17, no. 1, pp. 118-133, 2014.

[12] Artino, A. R., \& Stephens, J. M., "Academic motivation and self-regulation: A comparative analysis of undergraduate and graduate students learning online", The Internet and Higher Education, vol. 12, 146-151, 2009.DOI:10.1016/j.i heduc.2009.02.001.

[13] Park, S., \& Yun, H., "Relationships between motivational strategies and cognitive learning in distance education courses", Distance Education, vol. 38, no. 3, pp. 302-320, 2017. DOI:https://doi.org/10.1080/01587919.2017.136900 7

[14] Locascio, G., Mahone, E. M., Eason, S. H., \& Cutting, L. E., "Executive dysfunction among children with reading comprehension deficits", Journal of learning disabilities, vol. 43, no. 5, pp. 441-454, 2010. DOI: https://doi.org/10.1 177\%2F0022219409355476. 
[15] Bol, L., \& Garner, J. K., "Challenges in supporting self-regulation in distance education environments", Journal of Computing in Higher Education, vol. 23, no. 2-3, pp. 104-123, 2011. DOI: https://doi.org/10.1007/s12528-0 11-9046-7.

[16] Rotgans, J. I., \& Schmidt, H. G., "The intricate relationship between motivation and achievement: Examining the mediating role of self-regulated learning and achievement-related classroom behaviors", International Journal of Teaching and Learning in Higher Education, vol. 24, no. 2, pp. 197-208, 2012.

[17] Zimmerman, B. J., "Investigating self-regulation and motivation: Historical background, methodological developments, and future prospects", American educational research journal, vol. 45, no. 1, pp. 166-183, 2008. DOI: https://doi.org/10.3102\%2F0002831207312909.

[18] Garner, J. K., \& Tocker, M. B., "Relationships between executive functions, metacognitive awareness, and academic achievement in students with and without risk factors for executive dysfunction", Annual Meeting of the American Educational Research Association, April, Vol. 812, 2011.

[19] Bandura, A., "Self-efficacy: Toward a unifying theory of behavioral change. Psychological Review, vol. 84, no. 2, pp. 191-215, 1977. doi:10.1037/0033-295x.84.2.191.

[20] Bandura, A., Self-efficacy: The exercise of control. New York, NY: Worth. 1997.

[21] Sperry, A., "The Association Among Executive Functioning, Self-Efficacy and ADHD with Attitudes Towards Online Learning", Honors Theses, no. 2449, 2021. DOI: https://digitalworks.union.edu/theses/2449

[22] Honicke, T., and Broadbent, J., "The influence of academic self-efficacy on academic performance: a systematic review", Educ. Res. Rev, vol. 17, pp. 63-84, 2016. DOI: 10.1016/j.edurev.2015.11.002.

[23] Richardson, M., Abraham, C., and Bond, R., "Psychological correlates of university students' academic performance: a systematic review and meta-analysis", Psychol. Bull. Vol. 138, pp. 353-387, 2012. DOI: 10.1037/a0026838

[24] Yokoyama, S., "Academic self-efficacy and academic performance in online learning: A mini review", Frontiers in psychology, vol. 9, 2019, 2794. DOI: https://doi.org/10. 3389/fpsyg.2018.02794.

[25] Gopalan, V., Bakar, J. A. A., Zulkifli, A. N., Alwi, A., \& Mat, R. C., "A review of the motivation theories in learning", In AIP Conference Proceedings, vol. 1891, no. 1, 2017, pp. 020043. AIP Publishing LLC. DOI:https://doi.org/10.1063 1.5005376 .

[26] Mitchell, J. I., Gagné, M., Beaudry, A., \& Dyer, L., "The role of perceived organizational support, distributive justice and motivation in reactions to new information technology", Computers in Human Behavior, vol. 28, no. 2, pp. 729-738, 2012. DOI: https://doi.org/10.1016/j.chb.2011.11.021

[27] Yardimci, F., Bektaş, M., Özkütük, N., Muslu, G. K., Gerçeker, G. Ö., \& Başbakkal, Z., "A study of the relationship between the study process, motivation resources, and motivation problems of nursing students in different educational systems" Nurse education today, vol. 48, pp. 13-18, 2017. DOI: https://doi.org/10.1016/j.nedt.20 16.09.017.

[28] Ryan, R. M., \& Deci, E. L., "Intrinsic and extrinsic motivations: Classic definitions and new directions", Contemporary educational psychology, vol. 25, no. 1, pp. 54-67, 2000. DOI: https://doi.org/10.1006/ceps.1999.1020.

[29] Legault L., "Intrinsic and Extrinsic Motivation", Encyclopedia of Personality and Individual Differences, Springer International Publishing AG, 2016. DOI:10.1007/978-3-319-28099-8_1139-1, 1-4.

[30] Deci, E. L., \& Ryan, R. M., "Optimizing students' motivation in the era of testing and pressure: A self-determination theory perspective", in Building autonomous learners, Springer, Singapore., 2016, pp. 9-29.

[31] Tohidi, H., \& Jabbari, M. M., "The effects of motivation in education", Procedia-Social and Behavioral Sciences, vol. 31, pp. 820-824, 2012. DOI: https://doi.org/10.1016/j.sbspr o.2011.12.148.

[32] Council for higher education, "Higher education system 2019- 2020" (Hebrew), che, https://che.org.il/ (accessed on 14 December 2021).

[33] Roth, R. M., Lance, C. E., Isquith, P. K., Fischer, A. S., \& Giancola, P. R., "Confirmatory factor analysis of the behavior rating inventory of executive function-adult version in healthy adults and application to attention-deficit/hyperactivity disorder", Archives of clinical neuropsychology, vol. 28, no. 5, pp. 425-434, 2013. DOI: https://doi.org/10.1093/arclin/act031.

[34] Muris, P., "A brief questionnaire for measuring self-efficacy in youths", Journal of Psychopathology and behavioral Assessment, vol. 23, no.3, pp. 145-149, 2001. DOI: https://doi.org/10.1023/A:1010961119608

[35] Vallerand, R. J., Pe,lletier, L. G., Blais, M. R., Brière, N. M., Senécal, C. B., \& Vallières, É. F. "Academic motivation scale (AMS-C 28), college (CEGEP) version", Educational and Psychological Measurement, vol. 52, no. 53, pp. 1992-1993, 1993

[36] Steinberg, M., \& Morin, A. K., "Academic performance in a pharmacotherapeutics course sequence taught synchronously on two campuses using distance education technology", American journal of pharmaceutical education, vol. 75, no. 8, 2011. DOI: https://doi.org/10.5688/ajpe7581 50 .

[37] Klibanov, O. M., Dolder, C., Anderson, K., Kehr, H. A., \& Woods, J. A., "Impact of distance education via interactive videoconferencing on students' course performance and satisfaction", Advances in physiology education, vol. 42, no. 1, pp. 21-25., 2018. DOI: https://doi.org/10.1152/advan.00 113.2016.

[38] Klassen, R. M., "Confidence to manage learning: The self-efficacy for self-regulated learning of early adolescents with learning disabilities", Learning Disability Quarterly, vol. 33, no. 1, pp. 19-30, 2010. DOI: https://doi.org/10.117 7\%2F073194871003300102.

[39] Paananen, M., Aro, T., Viholainen, H., Koponen, T., Tolvanen, A., Westerholm, J., \& Aro, M., "Self-regulatory efficacy and sources of efficacy in elementary school pupils: 
The Relationship between Distance Learning, Executive Functions, and Academic Achievements

Self-regulatory experiences in a population sample and pupils with attention and executive function difficulties", Learning and Individual Differences, vol. 70, pp. 53-61, 2019. DOI: Dhttps://doi.org/10.1016/j.lindif.2019.01.003.
[40] Vallerand, R. J., \& Blssonnette, R., "Intrinsic, extrinsic, and amotivational styles as predictors of behavior: A prospective study", Journal of personality, vol. 60, no. 3, pp. 599-620., 1992. DOI: https://doi.org/10.1111/j.1467-6494. 1992.tb00922.x. 